JURNAL SEHAT MASADA VOLUME XV NOMOR $1 \quad$ Januari $2021 \quad$ ISSN : 1979-2344

\title{
PENGETAHUAN DAN SIKAP IBU HAMIL DALAM MENGKONSUMSI TABLET ZAT BESI DI PRAKTIK MANDIRI BIDAN 'I' KABUPATEN BANDUNG TAHUN 2019
}

\author{
Naili Rahmawati \\ Program Studi Diploma Tiga Kebidanan STIKes Dharma Husada Bandung \\ nailirahmawati.djati@gmail.com
}

\begin{abstract}
ABSTRAK
Angka anemia kehamilan di Indonesia menunjukkan nilai yang cukup tinggi. Angka anemia kehamilan trimester I $(3,8 \%)$, trimester II $(13,6 \%)$ dan trimester III $(24,8 \%)$. Anemia defisiensi zat besi adalah anemia yang terjadi akibat kekurangan zat besi dalam darah. Salah satu penyebab anemia pada kehamilan adalah kurangnya pengetahuan dan sikap negatif dalam mengkonsumsi tablet zat besi $(\mathrm{Fe})$. Tujuan penelitian untuk mengetahui pengetahuan dengan sikap ibu hamil dalam mengkonsumsi Fe di Praktik Mandiri Bidan 'I' Kabupaten Bandung Tahun 2019. Penelitian menggunakan prosedur penelitian deskriptif, dilaksanakan bulan Agustus sampai September 2019 . Populasi penelitian adalah seluruh ibu hamil yang melakukan pemeriksaan pada bulan Agustus sampai September 2019 dibidan I. Jumlah sampel 30 orang, diambil menggunakan teknik total sampling. Hasil penelitian, ibu hamil memiliki pengetahuan cukup (60\%), ibu hasil dengan pengetahuan baik (37\%), ibu hamil dengan pengetahuan kurang (3\%), ibu hamil dengan sikap positif dalam mengkonsumsi Fe (100\%). Kesimpulan penelitian adalah sebagian besar ibu hamil memiliki pengetahuan cukup dan semua ibu hamil memiliki sikap positif dalam mengkonsumsi Fe. Untuk meningkatkan pengetahuan dan sikap ibu hamil dalam mengkonsumsi Fe perlu dilakukan penyuluhan secara rutin dan peningkatan distribusi Fe oleh bidan dengan kerjasama dengan kader dan puskesmas.
\end{abstract}

Kata kunci : pengetahuan, sikap, ibu hamil, tablet besi

\begin{abstract}
Anemia rate of pregnancy in Indonesia shows a high enough value. Anemia in pregnancy trimester I $(3,8 \%)$, trimester II $(13,6 \%)$ and trimester III $(24,8 \%)$. Iron deficiency anemia is anemia that occurs due to a lack of iron in the blood. One of the causes of anemia in pregnancy is less knowledge and negative attitude in consuming iron tablet suplemen $(\mathrm{Fe})$. The objective of this study is to determine the knowledge and attitude of pregnant women in consuming iron tablet at the Midwives Independent Practice 'I' Bandung District of 2019. This study uses descriptive prosedure that conducted from Agustus to September of 2019. The study population was 30 people as sample were taken using total sampling technique. of pregnant women are included in the category of enough knowledge $(60 \%)$, pregnant women with good knowledge $(37 \%)$, less knowledge $(3 \%)$, pregnant women with a positive attitude in consuming $\mathrm{Fe}(100 \%)$. The conclusion is that most pregnant women included in the category of enough knowledge and all of pregnant women with a positive attitude in consuming $\mathrm{Fe}$. To increase the knowledge and attitude of pregnant women in consuming $\mathrm{Fe}$ is required a counseling routinely and incresed given of $\mathrm{Fe}$ by midwives and through collaboratiom with cadres and health centers.
\end{abstract}

Keywords : knowledge, attitude, pregnant women, iron tablet 


\section{PENDAHULUAN}

Ibu hamil mengalami peningkatan kebutuhan gizi, disamping untuk memenuhi kebutuhan dirinya juga untuk memenuhi kebutuhan janin yang dikandung. Anemia dapat terjadi ketika pola makan ibu hamil salah. ${ }^{1}$

Anemia defisiensi zat besi adalah penurunan jumlah sel darah merah yang disebabkan oleh zat besi yang terlalu sedikit. Besi merupakan komponen utama dari hemoglobin. Penyebab yang umum dari anemia adalah kekurangan zat besi. ${ }^{2}$

Pada ibu hamil terjadi peningkatan kebutuhan zat besi dua kali lipat akibat peningkatan volume darah tanpa ekspansi volume plasma, untuk memenuhi kebutuhan ibu (mencegah kehilangan darah pada saat melahirkan) dan pertumbuhan janin, hal ini lah yang menyebabkan seringnya kejadian anemia pada ibu hamil. ${ }^{3}$ Kebutuhan ibu hamil akan tablet zat besi (untuk pembentukan plasenta dan sel darah merah) sebesar 200-300\%. Perkiraan besaran zat besi yang perlu ditimbun selama hamil ialah $1.040 \mathrm{mg}$ dari jumlah ini, $200 \mathrm{mg} \mathrm{Fe}$ tertahan oleh tubuh ketika melahirkan dan $840 \mathrm{mg}$ sisanya hilang. ${ }^{4}$

Angka anemia kehamilan di Indonesia menunjukkan nilai yang cukup tinggi. Angka anemia kehamilan pada trimester I sebanyak : $3,8 \%$, trimester II yaitu $13,6 \%$ dan trimester III yaitu $24,8 \%$ dan tiap tahunnya wanita Indonesia meninggal karena kehamilan dan persalinan. Dari data tahun 2018, jumlah ibu hamil yang mengalami anemia paling banyak pada usia 15-24 tahun sebesar 84,6 persen, usia 25-34 tahun sebesar 33,7 persen,usia 35-44 tahun sebesar 33,6 persen dan usia 45-54 tahun sebesar 24 persen. $^{5}$

Penyebab anemia pada kehamilan adalah kekurangan zat besi, folat, dan vitamin B12. Kebutuhan harian zat besi dan asam folat saat hamil meningkat secara drastis (dua kali lipat) dari sebelum hamil. ${ }^{6}$

Anemia meningkatkan frekuensi komplikasi pada wanita hamil. Anemia dapat menyebabkan pendarahan antepartum dan post partum dan sering berakibat fatal, karena wanita yang anemia tidak dapat mentolerir kehilangan darah. Disamping itu juga bisa menyebabkan abortus, partus immatur dan prematur, gangguan proses persalinan seperti inertia, atonia, partus lama, pendarahan atonis, gangguan pada masa nifas sepeti sub involusi rahim, daya tahan terhadap infeksi dan stress, kurang prosuksi ASI rendah, dan gangguan pada janin seperti abortus, dismaturitas, makrosomi, berat bayi lahir rendah, kematian perinatal. $^{7}$

Penanganan anemia defesiensi besi salah satunya yaitu dengan memberikan suplementasi besi. Tingginya angka anemia pada ibu hamil perlu penanganan yang serius untuk menurunkan kejadian anemia. ANC dini, konsumsi tablet $\mathrm{Fe}$ secara rutin dan konsumsi gizi seimbang dapat mencegah terjadinya anemia. Tablet yang 
JURNAL SEHAT MASADA VOLUME XV saat ini banyak tersedia di praktik mandiri bidan dan puskesmas adalah tablet tambah darah yang berisi $60 \mathrm{mg}$ besi elemental dan $250 \mu \mathrm{g}$ asam folat. Bila dalam 90 hari muncul perbaikan, lanjutkan pemberian tablet sampai 42 hari pascasalin. ${ }^{8}$

Berdasarkan studi pendahuluan di BPM Bidan 'I' dari $10 \mathrm{ibu}$ hamil terdapat $3 \mathrm{ibu}$ hamil yang tidak rutin mengkonsumsi tablet zat besi dan kurang memahami manfaat tablet zat besi. Berdasar fenomena diatas peneliti tertarik untuk mengadakan penelitian untuk mengetahui pengetahuan dengan sikap ibu hamil dalam mengkonsumsi tablet zat besi di Praktik Mandiri Bidan I Kabupaten Bandung, Tahun 2019.

\section{METODOLOGI PENELITIAN}

Penelitian ini menggunakan prosedur penelitian deskriptif yang dilakukan pada bulan Agustus hingga september 2019 di Praktik Mandiri Bidan I Kabupaten Bandung. Populasi penelitian adalah seluruh ibu hamil yang melaksankan pemeriksaan pada bulan Agustus hingga September 2019 dibidan I, dengan jumlah sampel 30 orang yang diambil dengan menggunakan teknik total sampling.

Hasil ukur pengetahuan ibu hamil dalam mengkonsumsi zat besi yaitu :

$$
\begin{aligned}
& \text { 80\%-100\% : Baik } \\
& 60 \%-70 \% \text { : Cukup, } \\
& \text { 40\%-50\% : Kurang dan } \\
& \text { 20\% : Tidak baik. }
\end{aligned}
$$

Untuk hasil ukur sikap ibu hamil dalam mengkonsumsi zat besi yaitu $80 \%-100 \%$ menunjukkan sikap positif dan $65 \%-75 \%$ menunjukkan sikap negatif. Peneliti menggunakan data primer, yaitu data yang diperoleh dengan wawancara dg instrument kuesioner dan Analisis univariat.

\section{HASIL DAN PEMBAHASAN}

\section{a. Hasil Penelitian}

Hasil penelitian yang diperoleh dalam penelitian pengetahuan dengan sikap ibu hamil dalam mengkonsumsi tablet zat besi di Praktik Mandiri Bidan 'I' Kabupaten Bandung pada bulan agustus sampai september 2019.

Tabel 1 Distribusi Pengetahuan Ibu Hamil dalam Mengkonsumsi Tablet Zat Besi.

\begin{tabular}{lcc}
\hline $\begin{array}{l}\text { Kategori } \\
\text { pengetahuan }\end{array}$ & $\begin{array}{c}\text { Jumlah } \\
(\mathbf{f})\end{array}$ & Prosentase (\%) \\
\hline Baik & 11 & 37 \\
\hline Cukup & 18 & 60 \\
\hline Kurang & 1 & 3 \\
\hline Total & 30 & 100 \\
\hline Sumber : data primer 2019 &
\end{tabular}

Tabel 1, menunjukkan bahwa sebagian besar ibu hamil memiliki pengetahuan cukup sebesar $60 \%$, diikuti $37 \%$ ibu hamil dengan pengetahuan baik, dan 3\% ibu hamil dengan pengetahuan kurang. 
JURNAL SEHAT MASADA VOLUME XV

Tabel 2 Distribusi Sikap Ibu Hamil dalam Mengkonsumsi Tablet Zat Besi.

\begin{tabular}{lcc}
\hline Kategori sikap & $\begin{array}{c}\text { Jumlah } \\
(\mathrm{f})\end{array}$ & $\begin{array}{c}\text { Prosentase } \\
(\%)\end{array}$ \\
\hline Positif & 30 & 100 \\
\hline Negatif & 0 & 0 \\
\hline Total & 30 & 100 \\
\hline Sumber : data primer 2019 & &
\end{tabular}

Tabel 2 menunjukkan bahwa semua ibu hamil memiliki sikap positif (100\%).

\section{b. Pembahasan}

Tabel 1. menunjukkan bahwa sebagian besar ibu hamil memiliki pengetahuan cukup. Pengetahuan pada penelitian ini meliputi tentang pengertian tablet zat besi, fungsi zat besi, waktu yang dianjurkan dalam mengkonsumsi zat besi dan informasi lainya dapat diperoleh ibu hamil melalui penyuluhan yang diberikan bidan dalam kunjungan ANC.

Pengetahuan yang cukup dapat disebabkan oleh berbagai faktor termasuk faktor pengalaman dan pendidikan. ${ }^{9} \mathrm{Hal}$ ini didukung oleh penelitian yang menjelaskan bahwa pengetahuan memiliki hubungan yang erat dengan pendidikan, diharapkan dengan pendidikan yang tinggi maka akan semakin luas pula pengetahuannya. ${ }^{10}$

Hal ini juga sama dengan penelitian yang menunjukkan bahwa tingkat pengetahuan ibu hamil tentang tablet $\mathrm{Fe}$ secara umum termasuk dalam kategori cukup sejumlah 29 responden $(53.7 \%){ }^{11}$
NOMOR $1 \quad$ Januari 2021

ISSN : 1979-2344

Pengetahuan adalah informasi atau maklumat yang diketahui atau disadari oleh seseorang. ${ }^{12}$

Jenis pengetahuan ada 2, yaitu pengetahuan implisit dan pengetahuan eksplisit. Pengetahuan implisit adalah pengetahuan yang masih tertanama dalam bentuk pengalama seseorang dan berisi faktor-faktor yang tidak bersifat nyata seperti keyakinan pribadi, perspektif dan prinsip. Sedangan pengetahuan eksplisit adalah pengetahuan yang telah didokumentasikan atau disimpan dalam wujud nyata, bisa dalam bentuk perilaku kesehatan. Pengetahuan nyata di deskripsikan dalam tindakan-tindakan yang berhubungan dengan kesehatan. ${ }^{12}$

Tahapan pengetahuan menurut Benjamin S. Bloom (1956) ada 6 yaitu Tahu (know) : kemampuan untuk mengenali dan mengingat peristilahan, definisi, fakta-fakta, gagasan, pola, urutan, metodologi, prinsip dasar, dan sebagainya, kemudian memahami (comprehension): kemampuan untuk menjelaskan secara benar tentang objek yang diketahui, dan dapat menginterpretasikan materi tersebut secara benar, selanjutnya aplikasi (application): kemampuan untuk menggunakan materi tersebut secara benar, kemudian analisis (analysis) kemampuan untuk menjabarkan materi atau suatu objek ke dalam komponenkomponen, tetapi masih di dalam satu struktur organisasi dan masih ada kaitannya satu sama lain, selanjutnya sintesis (synthesis) kemampuan untuk meletakkan 
JURNAL SEHAT MASADA VOLUME XV

atau menghubungkan bagian-bagian di

dalam suatu bentuk keseluruhan yang baru, dan terakhir adalah evaluasi (evaluation) kemampuan untuk melakukan justifikasi atau penilaian terhadap suatu materi atau objek. ${ }^{12}$

Berdasarkan Tabel 2. menunjukkan bahwa semua ibu hamil memiliki sikap positif. Pada penelitian ini sikap dibagi menjadi 2 kategori yaitu kategori positif dan kategori negatif.

Hal ini berbeda dengan penelitian yang dilakukan oleh Rita Kirana (2010) dengan penelitian ini, yaitu dari kategori sikapnya. Penelitian oleh Riara Kirana menggunakan 3 kategori, yaitu sikap baik, kurang dan cukup dan didapatkan bahwa sikap ibu hamil tentang konsumsi tablet zat besi $(\mathrm{Fe})$ sebagian responden dengan sikap kurang 10 responden (25\%), sikap cukup yaitu 18 responden $(45 \%)$ dan sikap baik 12 responden $(30 \%){ }^{13}$

Sikap yang ada pada seseorang memerlukan unsur respons dan stimulus. Kepuasan merupakan respons dari stimulus yang diterima yaitu pelayanan kesehatan. Ouput sikap pada seseorang dapat berbeda, jika suka maka seseorang akan mendekat, mencari tahu, dan bergabung, sebaliknya jika tidak suka maka seseorang akan menghindar atau menjauh. ${ }^{12}$

Menurut Fishbein dan Ajzen (1975) sikap adalah suatu predisposisi yang dipelajari untuk merespons secara positif atau negatif terhadap suatu objek, situasi, konsep atau orang. ${ }^{12}$
NOMOR $1 \quad$ Januari 2021

ISSN : 1979-2344

Faktor-faktor yang mempengaruhi sikap adalah pengalaman pribadi yaitu pengalaman yang telah didapatkan sebelumnya akan menjadi pembelajaran yang akan membentuk sikap, kemudian pengaruh orang lain yang dianggap penting : orang lain di sekitar kita merupakan salah satu di antara komponen sosial yang ikut mempengaruhi sikap kita. Seseorang yang kita anggap penting akan banyak mempengaruhi pembentukan sikap kita terhadap sesuatu, selanjutnya pengaruh budaya : kebudayaan mempunyai pengaruh besar terhadap pembentukan sikap kita terutama kebudayaan di mana kita hidup dan dibesarkan, kemudian media massa : berbagai bentuk media massa seperti televisi, radio, surat kabar, majalah, dan lain-lain mempunyai pengaruh besar dalam pembentukan opini dan kepercayaan orang. Kemudian lembaga pendidikan dan lembaga agama : kedua lembaga di atas, mempunyai pengaruh dalam pembentukan sikap karena keduanya meletakkan dasar pengertian dan konsep moral dalam diri individu. Pemahaman akan baik dan buruk, garis pemisah antara sesuatu yang boleh dan tidak boleh dilakukan, diperoleh dari pendidikan dan pusat keagamaan serta ajarannya. Selanjutnya pengaruh faktor emosional adalah suatu bentuk sikap merupakan pernyataan yang didasari oleh emosi yang berfungsi sebagai penyaluran frustasi atau pengalihan bentuk mekanisme pertahanan ego. Sikap ini dapat merupakan sikap yang sementara dan segera berlalu begitu frustasi 
JURNAL SEHAT MASADA VOLUME XV telah hilang. Akan tetapi dapat pula merupakan sikap yang dapat bertahan lama. 14

Tahapan sikap dalam taksonomi Bloom (1956) tahapan domain sikap adalah sebagai berikut Tahap sikap menerima adalah kepekaan seseorang dalam menerima rangsangan (stimulus) dari luar yang datang kepada dirinya dalam bentuk masalah, situasi, gejala, dan lain-lain. Termasuk dalam jenjang ini, misalnya adalah kesadaran dan keinginan untuk menerima stimulus, mengontrol dan menyeleksi gejalagejala atau rangsangan yang datang dari luar. Receiving atau attenting juga sering diberi pengertian sebagai kemauan untuk memperhatikan suatu kegiatan atau suatu objek. Pada tahap ini, seseorang dibina agar mereka bersedia menerima nilai-nilai yang diajarkan kepada mereka, dan mau menggabungkan diri ke dalam nilai tersebut atau mengidentifikasikan diri dengan nilai tersebut. Sebagai contoh, seorang ibu menerima bahwa bayi harus secara rutin dibawa ke posyandu untuk ditimbang agar dapat menilai pertumbuhan dan perkembangannya. ${ }^{12}$

Kemudian tahap sikap menanggapi, Tahap sikap menanggapi adalah kemampuan yang dimiliki oleh seseorang untuk mengikutsertakan dirinya secara aktif dalam fenomena tertentu dan membuat reaksi terhadapnya salah satu cara. Tahap ini lebih tinggi daripada tahap menerima. Selanjutnya tahap menilai. Tahap sikap menilai adalah memberikan nilai atau memberikan
NOMOR 1 Januari 2021 ISSN : 1979-2344 penghargaan terhadap suatu kegiatan atau objek, sehingga apabila kegiatan itu tidak dikerjakan, dirasakan akan membawa kerugian atau penyesalan. Menilai merupakan tingkat afektif yang lebih tinggi lagi dari pada menerima dan menanggapi. Dalam kaitan dalam perubahan perilaku, seseorang di sini tidak hanya mau menerima nilai yang diajarkan, tetapi mereka telah berkemampuan untuk menilai konsep atau fenomena, yaitu baik atau buruk. Bila suatu ajaran yang telah mampu mereka nilai dan mampu untuk mengatakan "itu adalah baik", maka hal ini berarti bahwa seseorang telah menjalani proses penilaian. Nilai tersebut mulai dicamkan (internalized) dalam dirinya. Dengan demikian nilai tersebut telah stabil dalam dirinya. Kemudian tahap mengelola : Tahap sikap mengelola adalah mempertemukan perbedaan nilai sehingga terbentuk nilai baru yang universal, yang membawa pada perbaikan umum. Mengatur atau mengorganisasikan merupakan pengembangan dari nilai ke dalam satu sistem organisasi, termasuk di dalamnya hubungan satu nilai dengan nilai lainnya, pemantapan dan perioritas nilai yang telah dimilikinya. Kemudian tahap menghayati : keterpaduan semua sistem nilai yang telah dimiliki oleh seseorang, yang memengaruhi pola kepribadian dan tingkah lakunya. Di sini proses internalisasi nilai telah menempati tempat tertinggi dalam suatu hirarki nilai. Nilai tersebut telah tertanam secara konsisten pada sistemnya dan telah mempengaruhi emosinya. Menghayati 
JURNAL SEHAT MASADA VOLUME XV merupakan tingkat efektif tertinggi, karena tahap sikap ini telah benar-benar bijaksana. Menghayati telah masuk pada pemaknaan yang telah memiliki philosophy of life yang mapan. Jadi, pada tahap ini peserta didik telah memiliki sistem nilai yang telah mengontrol tingkah lakunya untuk suatu waktu yang lama, sehingga membentuk karekteristik "pola hidup" tingkah lakunya menetap, konsisten, dan dapat diamalkan. ${ }^{12}$

\section{KESIMPULAN}

Sebagian besar ibu hamil memiliki pengetahuan cukup sebesar $60 \%$ dan semua ibu hamil memiliki sipak positif (100\%).

\section{DAFTAR PUSTAKA}

1. Ojofeitimi EO, Ogunjuyigbe PO, Sanusi, et al. Poor Dietary Intake of Energy and Retinol among Pregnant Women: Implications for Pregnancy Outcome in Southwest Nigeria. Pak. J. Nutr. 2008; 7(3):480-484.

2. Proverawati, Atikah. Anemia dan Anemia Kehamilan. Yogyakarta: Nuha Media, 2011.

3. Cunningham dan Garry F. Obstetri Williams Edisi 21 Vol 2 [Hartono et al., trans]. 2001. Buku Kedokteran EGC : Jakarta

4. Arisman. Buku Ajar Ilmu Gizi: Gizi dalam Daur Kehidupan, Jakarta: EGC, 2009.

5. Riset Kesehatan Dasar (Riskesdas). 2018. Badan Penelitian dan Pengembangan Kesehatan Kementerian RI.

6. Husin, Farid. 2014. Asuhan Kehamilan Berbasis Bukti Paradigma Baru dalam Asuhan Kehamilan. Sagung Seto : Jakarta.
NOMOR 1 Januari 2021

ISSN : 1979-2344

7. Rukiyah, dkk. et al. 2010. Asuhan Kebidanan 1 . CV. Trans Info Media : Jakarta

8. Mengkuji dkk, 2012 Asuhan Kebidanan 7 langkah SOAP. EGC : Jakarta.

9. Notoatmodjo, S. 2010. Promosi Kesehatan dan Ilmu Prilaku. Rineka Cipta : Jakarta

10.Wawan dan Dewi. 2010. Teori dan pengukuran Pengetahuan. Yogyakarta: Nuha Medika

11.Wigunantiningsih, Ana. 2011. “ Tingkat pengetahuan ibu hamil tentang tablet $\mathrm{Fe}$ di BPS Sulastri Wonolopo Tasikmadu Karanganyar vol. 4 (April 2011) http://ejurnal.mithus.ac.id/index.php/mat ernal/article/download/142/127 (diakses 12 Januari 2021).

12.Budiman, Agus Riyanto. Kapita Selekta Kuesioner Pengetahuan dan Sikap dalam Penelitian Kesehatan. Jakarta: Salemba Medika, 2013

13.Kirana, Rita. 2010. Pengetahuan dan Sikap Ibu Hamil terhadap Konsumsi Tablet Fe di Puskesmas Murung Pudak Kabupaten Tabalong Tahun 2010 http://perpustakaan.litbang.depkes.go.id/ otomasi/index.php?p=show_deta il\&id=32702 (diakses tanggal 12 januari 2020).

14.Azwar,S. 2007. Penyusunan Skala Psikologi. Yogyakarta : Pustaka Belajar 